\title{
THE EFFECT OF KINEMATICS PARAMETER ON A SOD CUTTING PERFORMANCE
}

\author{
*S. H. Desoky
}

\section{ABSTRACT}

A sod cutting machine was designed and constructed for cutting sod layers to be ready for using in garden and club landscape. Experiments were carried out to improve its performance and minimize the operational cost. The performance of the sod cutting machine in terms of "productivity, cutting efficiency, cutting energy, and cost was investigated as a function of change in kinematics parameter (ratio of rotor peripheral velocity to forward speed), rotor radius and cutting depth. The experimental results revealed that the use of the fabricated sod cutting machine maximized cutting efficiency to $85 \%$ and minimized both energy by $20 \%$ and cost to $2.2 \mathrm{LE} / \mathrm{m}^{2}$ under the following conditions:

1. Operating of the manufactured machine at a kinematic parameter of 4.0 which corresponded to forward speed of $1.2 \mathrm{~km} / \mathrm{h}$, knife velocity of $1.36 \mathrm{~m} / \mathrm{s}$ and rotor radius of $1.3 \mathrm{~cm}$.

2. Adjusting of the knife of the manufactured machine prototype at cutting depth of $3 \mathrm{~cm}$.

\section{INTRODUCTION}

$\mathrm{P}$ ublic and special gardens play a vital role in the population life. The green bed (Sod) refines the atmosphere from the bad particles of pollution in the air. Green bed is used widely as a playground for most games in different clubs. Sod had to be cut at such periods to be ready for using. This process is still operated depending on primitive methods using manual tools. So, sod cutting by means of up to date technology taking into consideration machine efficiency, durability, energy, and cost is an important question to be answered.

\footnotetext{
* Assist. Prof. of Agric. Eng., Faculty of Agric. Eng. Cairo, Al-Azhar Univ.
} 
Many researches were carried out on the shearing mechanisms of cutting machines and the design variables which affect the cutting energy. But data concerning sod cutting, machines and their performance were not available. Kepner et al. (1992) stated that the common way of the cutting forces was by means of two opposed shearing elements. In the way of applying the cutting forces by single cutting elements, the material being cut may transmit the force required to oppose a single cutting element. An impact cutter having a single high speed cutting element relies primarily upon inertia of the material being cut to furnish the opposing required force for shear. Prasad and Cupta (1999) found that the cross section area and moisture content of the cut material had significant influence over shearing energy and maximum shearing force, Awady et al. (1992) indicated that the power requirement for cutter bar of the reciprocating knife was only $1.7 \mathrm{~kW} / \mathrm{m}$ width of cut while the power requirement for horizontal rotary knife was ranged from as little as $5 \mathrm{~kW} / \mathrm{m}$ up to $10 \mathrm{kVWm}$ width of cut. Desoky (2005) found that the required force for cutting any material may be divided into two parts. The first part is the inertia force required to move the cutting mechanism, and the second is the shearing force required to shear the material. Inertia force is affected by the square of knife velocity resulting in a sharp increase of cutting energy. The force was found to affect by knife velocity, machine forward speed, and material moisture content.

The objectives of the present research are:

1. Fabricating sod cutting machine to improve its performance and minimize the operational cost.

2. Evaluation of the machine from the economic point of view.

Morad and Kador (2012) showed that fabricate a sod cutting machine was less energy.

\section{MATERIALS AND METHODS}

Experiments were carried out at Salihuh farm Asmaeelyh Governorate, at season 2016. A sod cutting machine is fabricated in locally workshop 
and devaluate its performance under different operating parameters. The experiment area was 15 feedans.

The sod cutting machine shown in (Fig. 1) was made especially for this work. The machine consists of the following main parts:

1. Engine: The sod cutting machine engine is a 4-strokc, two cylinders petrol engine and air cooled. The engine power is $4 \mathrm{~kW}$ at $3560 \mathrm{rpm}$ and the fuel tank capacity is 4 liters. The engine is started manually by a robe. The fuel air ratio is controlled by means of throttle wire attached to the steering hand.

2. Power transmission: The power transmission system mainly consists of:

- Primary transmission reduction system.

- Gearbox. To reduce the speed from $3500 \mathrm{rpm}$ to $1500 \mathrm{rpm}$ at reduction ratio $(2.6: 1)$.

- Transmission system for cutting mechanism and wheels.

3. The wheels: Two types of wheels were supplemented to the sod cutting machine: the first are driving wheels having lugs to improve the machine traction. The second type is a pneumatic wheel behind the machine used to stabilize and absorb the machine vibrations.

Transmission system for cutting mechanism and wheels: The motor power is transmitted through a pulley of $6 \mathrm{~cm}$ diameter fixed on the motor shaft. The motor shaft transmits the power to three pulleys, the pulley takes its power from the motor through V-shaped rubber belt, and transmits the power to the gear fixed at the same shaft and finally transmits the power to the machine wheels through another gear and a sprocket.

The cutting system: The cutting process is achieved through two modes of cutting, The first mode is achieved by a horizontal knife which has $46 \mathrm{~cm}$ long, $6 \mathrm{~cm}$ wide and $0.6 \mathrm{~cm}$ thick. The second mode is achieved by horizontal knife which has two upper and one lower angle namely: frontal clearance, rake and bottom clearance angels. The frontal clearance and rake angles are inclined by $45^{\circ}$ and $75^{\circ}$ with the horizontal respectively. The frontal clearance angle reduces the knife area of contact; also the rake angle helps in raking the cutting area. 


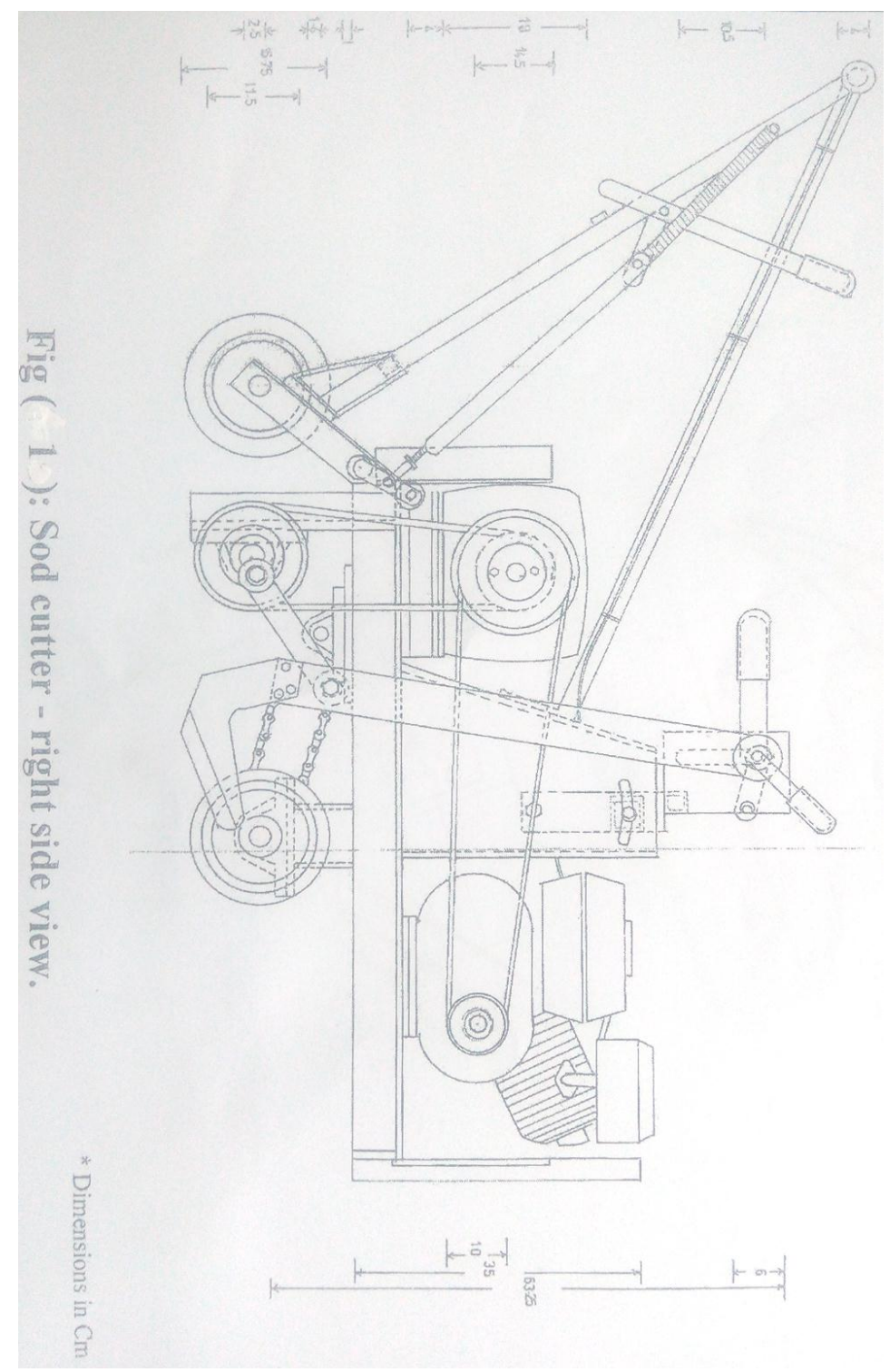

- Kinematic parameter adjustment: The kinematic parameter was defined as the ratio of knife peripheral velocity to machine forward speed:

$$
\lambda=\omega \mathrm{r} / \mathrm{v}
$$

Where:

$\lambda$ : Kinematics parameter.

$\omega$ : Angular velocity of the knife, $\mathrm{rad} / \mathrm{s}$

$\mathrm{r}$ : Rotor radius, $\mathrm{m}$. 
$\mathrm{v}:$ Machine forward speed, $\mathrm{m} / \mathrm{s}$

The proper adjustment of the kinematic parameter during sod cutting is of great importance to decrease sod cutting losses and consequently increase cutting efficiency.

There were three ways in which the kinematic parameter can be varied:

a. Change the rotor radius.

b. Change the knife velocity.

c. Change machine forward speed.

So, in the present investigation, combination of the above mentioned factors were taken into consideration to obtain different kinematic parameter for selecting the optimum value as follows:

1. The rotor of the reciprocating - slider mechanism in the manufactured machine is adjusted in such a case that can be changed to be 1.3 and $2.2 \mathrm{~cm}$ which corresponded to 4 and $5.5 \mathrm{~cm}$ the stroke length.

2. The knife peripheral velocity could be changed to be $800 \mathrm{rpm}(1.10$ $\mathrm{m} / \mathrm{s}) 1000 \mathrm{rpm}(1.36 \mathrm{~m} / \mathrm{s}), 1170 \mathrm{rpm}(1.6 \mathrm{~m} / \mathrm{s}), 1350 \mathrm{rpm}(1.84 \mathrm{~m} / \mathrm{s})$ under rotor radius of $1.3 \mathrm{~cm}$. Also, the knife velocity could be changed to be $800 \mathrm{rpm}(1.70 \mathrm{~m} / \mathrm{s}) 1000 \mathrm{rpm}(2.1 \mathrm{~m} / \mathrm{s}), 1170 \mathrm{rpm}(2.45 \mathrm{~m} / \mathrm{s})$, $1350 \mathrm{rpm}(2.83 \mathrm{~m} / \mathrm{s})$ under rotor radius of $1.3 \mathrm{~cm}$.

3. The machine is operated at four different forward speeds of $0.9,1.2$, 2.0 and $2.4 \mathrm{~km} / \mathrm{h}$.

- By using equation, the kinematic parameters values can be determined (Tables:2, 3)

- The performance of the manufacture sod cutting machine was calculated as a function of change in kinematic parameter (as mentioned in Table, 2) and cutting depths of 2, 3, and $5 \mathrm{~cm}$.

- Evaluation of the manufactured sod cutting machine performance was carried out by taking into consideration the following indicators:

- Machine productivity (MP): It was calculated using the following equation:

$$
\mathrm{MP}=1 / \mathrm{T}
$$

Where:

T: Effective time consumed for cutting sod, $\mathrm{h} / \mathrm{m}^{2}$. 
Table (2): Kinematic parameter values at rotor radius of 1.3.

\begin{tabular}{|l|c|c|c|c|c|c|c|c|c|c|c|c|c|c|c|c|c|}
\hline $\begin{array}{l}\text { Knife } \\
\text { velocity, } \\
\text { m/s }\end{array}$ & \multicolumn{9}{|c|}{1.10} & \multicolumn{3}{|c|}{1.36} & \multicolumn{3}{c|}{1.60} & \multicolumn{3}{c|}{1.84} \\
\hline $\begin{array}{l}\text { Forward } \\
\text { speed, } \\
\text { km/h }\end{array}$ & 0.9 & 1.2 & 2.0 & 2.4 & 0.9 & 1.2 & 2.0 & 2.4 & 0.9 & 1.2 & 2.0 & 2.4 & 0.9 & 1.2 & 2.0 & 2.4 \\
\hline $\begin{array}{l}\text { Kinematic } \\
\text { parameters }\end{array}$ & 4.4 & 3.3 & 2.0 & 1.7 & 5.4 & 4.0 & 2.5 & 2.0 & 6.4 & 4.8 & 2.9 & 2.4 & 7.4 & 5.5 & 3.3 & 2.8 \\
\hline
\end{tabular}

Table (3): Kinematic parameter values at rotor radius of $\mathbf{2 . 0}$.

\begin{tabular}{|l|c|c|c|c|c|c|c|c|c|c|c|c|c|c|c|c|}
\hline $\begin{array}{l}\text { Knife } \\
\text { velocity, } \\
\text { m/s }\end{array}$ & \multicolumn{9}{|c|}{1.70} & \multicolumn{3}{|c|}{2.10} & \multicolumn{3}{|c|}{2.45} & \multicolumn{3}{c|}{2.83} \\
\hline $\begin{array}{l}\text { Forward } \\
\text { speed, } \\
\text { km/h }\end{array}$ & 0.9 & 1.2 & 2.0 & 2.4 & 0.9 & 1.2 & 2.0 & 2.4 & 0.9 & 1.2 & 2.0 & 2.4 & 0.9 & 1.2 & 2.0 & 2.4 \\
\hline $\begin{array}{l}\text { Kinematic } \\
\text { parameters }\end{array}$ & 6.8 & 5.1 & 3.1 & 2.6 & 8.4 & 6.3 & 3.8 & 3.2 & 9.8 & 7.4 & 4.4 & 3.7 & 11.3 & 8.5 & 5.1 & 4.3 \\
\hline
\end{tabular}

\section{- Cutting efficiency $\left(\zeta_{c}\right)$ :}

It was calculated using the following formula:

$$
\zeta_{\mathrm{c}}=\mathrm{MP}-\mathrm{ML} / \mathrm{MP}
$$

Where: ML: Machine sod losses, $\mathrm{m}^{2} / \mathrm{h}$

- Power requirement: Estimation of the required brake horsepower to operate machine was carried out by accurately measuring the decrease in fuel level in the fuel tank immediately after executing each operation. The required power was calculated by using the following formula:

Where:

$$
\text { Power }(\mathbf{h p})=W_{f} * \mathbf{C V} * \zeta_{\mathrm{f}}, * \mathbf{e}_{\mathrm{th}} \quad(\mathrm{kW})
$$

$\mathrm{W}_{\mathrm{f}}$ : Rate of fuel consumption, $\mathrm{kg} / \mathrm{s}$,

C.V.: Calorific value of fuel, $\mathrm{kcal} / \mathrm{kg}$,

$\zeta_{f}$ : Thermal efficiency.

$\mathrm{e}_{\mathrm{th}}$ : Thermo - mechanical equipment equivalent.

-Energy requirements: It can be calculated by using by using the following equation,

Energy req. $\left(\mathrm{kW} / \mathrm{h} \cdot \mathrm{m}^{2}\right)=$ required power $(\mathrm{kW}) /$ machine productivity $\left(\mathrm{m}^{2} / \mathrm{h}\right)$

- Cost analysis: It can be calculated by using by the straight line method.

The operational cost was determined using the following equation; 
Operating cost $=$ machine cost $/$ machine productivity

The criterion cost was determined using the following equation (Awady etal, 1982)

Criterion cost $=$ operating cost + product losses cost

\section{RESULTS AND DISCUSSION}

\section{1- Effect of the kinematics parameter (K.P) on sod cutting productivity and cutting depth:}

Fig (2) shown the effect of kinematics parameter on the sod cutting machine proto - type at three different cutting level of depth 2, 3 and 4 $\mathrm{cm}$ (layers thickness) the productivity was increasing from $220 \mathrm{~m}^{2} / \mathrm{h}$ at 2 $\mathrm{cm}$ depth to $800 \mathrm{~m}^{2} / \mathrm{h}$ at the max level and decrease to $600 \mathrm{~m}^{2} / \mathrm{h}$ through kinematics parameters change at 1,4 and 6. Same change was done through the depth of $3 \mathrm{~cm}$, the productivity was $500 \mathrm{~m}^{2} / \mathrm{h}$ at kinematics parameter one and increase to $1000 \mathrm{~m}^{2} / \mathrm{h}$ at K.P. 4 and decrease to 770 $\mathrm{m}^{2} / \mathrm{h}$ at the K.P. 6. Productivity also was 350,1200 and $690 \mathrm{~m}^{2} / \mathrm{h}$ at kinematics parameter one, 4 and 6 respectively, also through cutting depth of $4 \mathrm{~cm}$. Although the max productivity was dispatch at K.P 4 and at cutting depth $4 \mathrm{~cm}$, but it would be in the best at the same K.P. and the depth of $3 \mathrm{~cm}$, Because the cutting quality of the layer in the best condition.

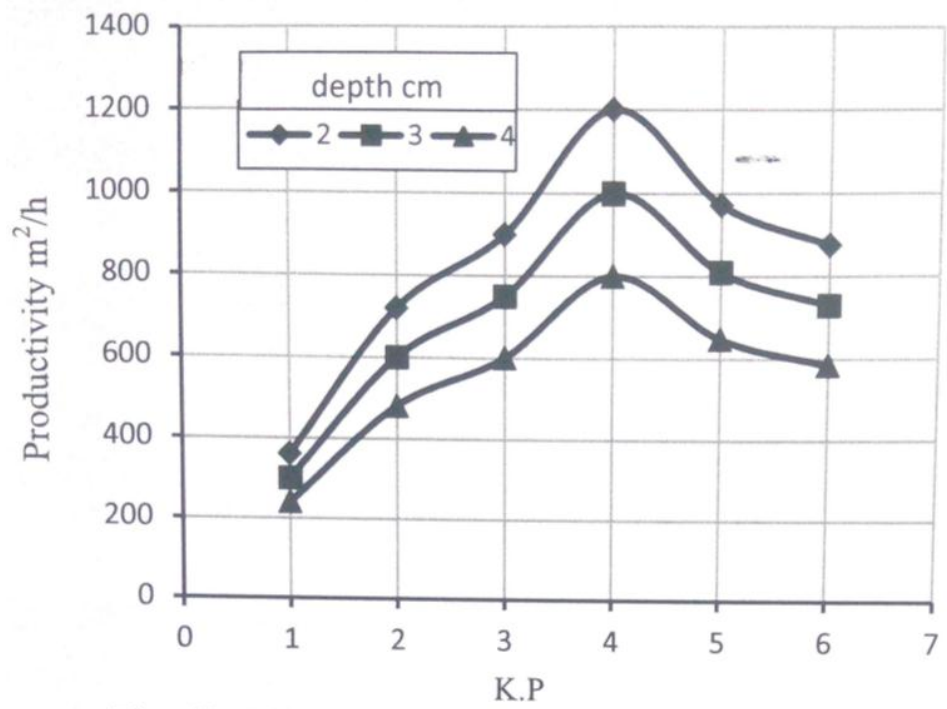

Fig. (1): Effect of kinematics parameter on Productivity $\mathrm{m}^{2} / \mathrm{h}$ at different depth $\mathrm{cm}$. 
2- Effect of the kinematics parameter (K.P) on sod cutting operating cost:

Fig (3) demonstrate the effect of kinematics parameter on the sod cutting operating cost at three different cutting level of depth. From the results the optimum kinematic parameter was equal 4 and also the best quality of depth cut was at the level $3 \mathrm{~cm}$. the operating cost should be one $\mathrm{LE} / \mathrm{m}^{2}$.

\section{3- Effect of the kinematics parameter (K.P) on the energy requirement:}

Fig (4) shown the effect of the kinematics parameter on the energy requirement, $\mathrm{kw} \cdot \mathrm{h} / \mathrm{m}^{2}$, at three cutting depth. Also from the previous results the optimum kinematic parameter was at 4 and the best quality of depth cut was at the level $3 \mathrm{~cm}$ from the result the energy required should be at $8.5 \mathrm{~kW} \cdot \mathrm{h} / \mathrm{m}^{2}$.

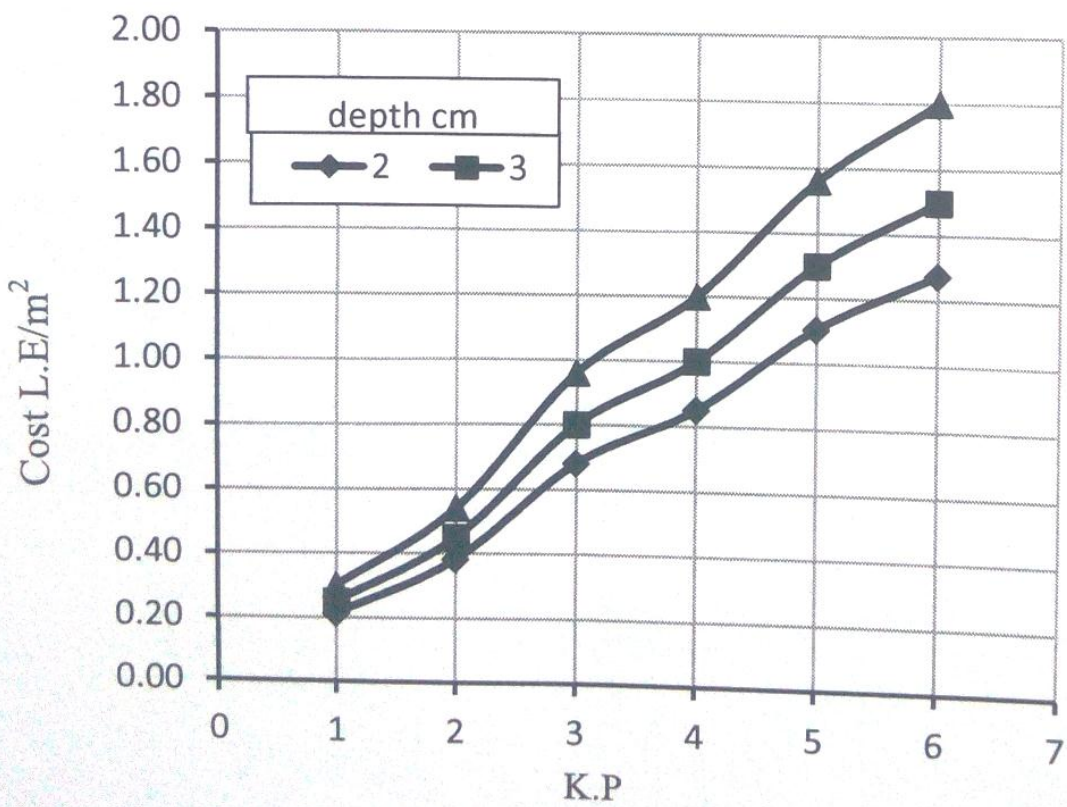

Fig. (2): Effect of kinematics parameter on Cost L.E $/ \mathrm{m}^{2}$ at different depth $\mathrm{cm}$. 


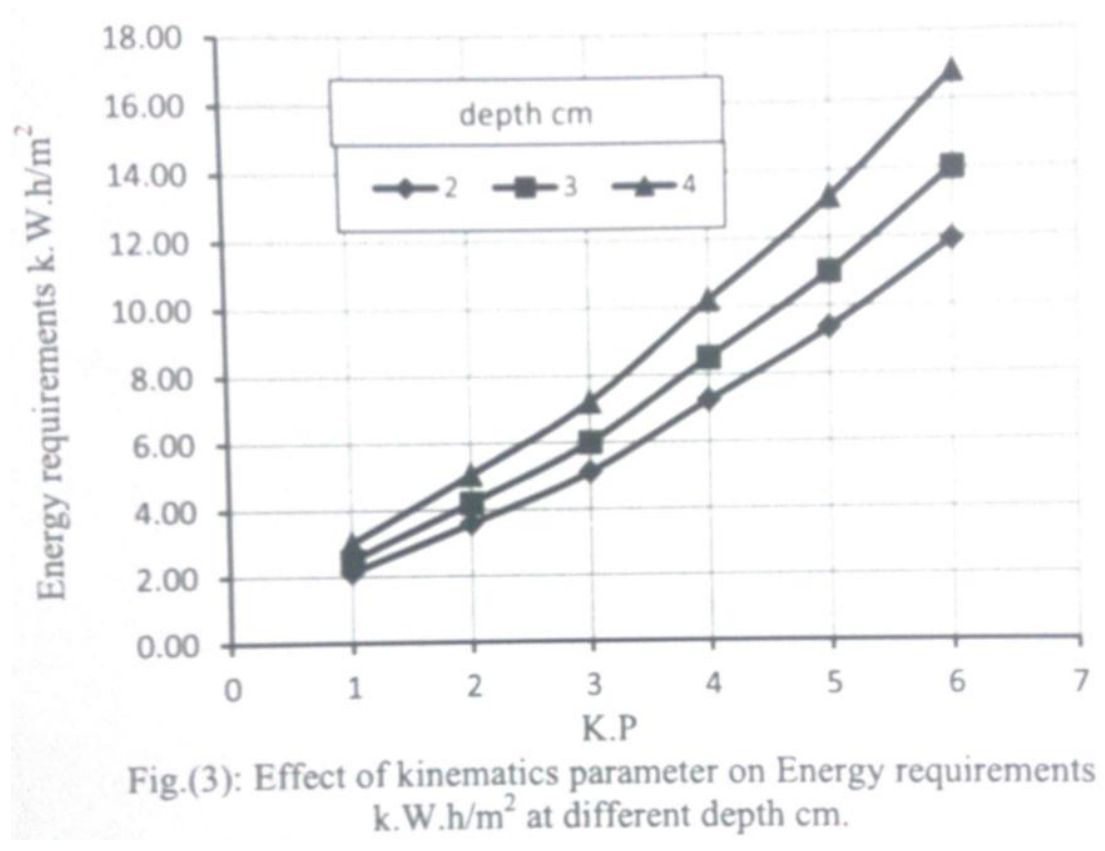

\section{CONCLUSION}

The present research aimed to construct and fabricate of a sod cutting machine and optimize some operating parameters affecting its performance. From the results, it can be concluded that:

1- Criterion cost as well as energy requirements can be minimized and cutting efficiency can be maximized when kinematic parameter of 4.0 is adjusted. (Kinematic parameter of 4.0 is corresponded to $1.36 \mathrm{~m} / \mathrm{s}$ knife velocity, $1.2 \mathrm{~km} / \mathrm{h}$ forward speed, and $1.3 \mathrm{~cm}$ rotor radius).

2- Sod layers are with high quality when the cutting depth of $3 \mathrm{crn}$ is adjusted during the cutting operation using the manufactured sod cutting machine.

\section{REFERENCES}

Awady, M.N.; E.Y. Ghoneim. And A.I. Hashish (1992). A critical comparison between wheat combines harvesters under Egyptian conditions. Res. Bull. No.1920. Ain Shams Univ.; 1 - 13.

Barger, E.L; J.B.Liedoh; W.M. Carietion; and E.G. Makibben (1963). Tractor and their power units $2^{\text {nd }}$ ed., John Wiley Sons. Inc.,New York. U.S.A. P: 211-213.

Desoky, S.H. (2005). Development of sod cutter PHD Ag. Eng. Dpt, 
Azhar Univ. P: 28-30.

Kepner, R.A.; R. Bainer; and E.L. Barger (1992). Principle of farmmachinery. $3^{\text {rd }}$ ed., Te AVI pub. Co., U.S.A: 341 - 357.

Morad, M.M and U.A. Kadour (2012). A study on the energy requirements for the cutting operation 27 th conference of $\mathrm{Ag}$. Eng., October P: 45-58.

Prosod, J, and C.P. Gupta (1999). Mechanical properties of maize stalk as related to harvesting. J. Agric. Eng., Res., 20: 79-87

Waltham, R.G. and F. Roymond (1998). Forage conservation and feeding farming press limited. P: 65 - 85.

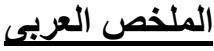

\section{تأثير العامل الكينماتيكى على أداء آلة قطع شرائح النجيل}

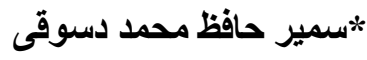

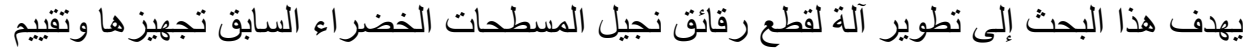

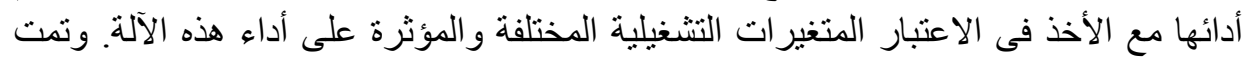

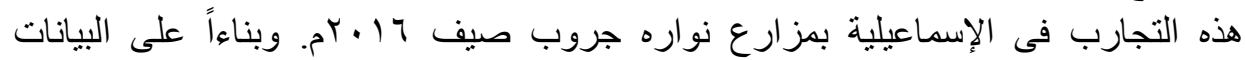
المتحصل عليها يمكن التوصيات بالآتى:

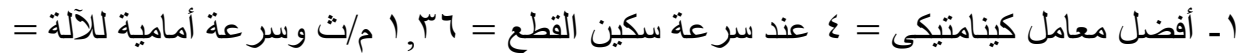

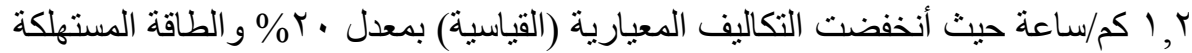

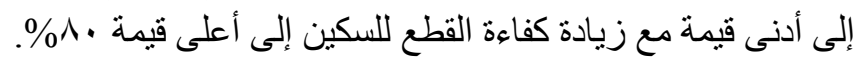

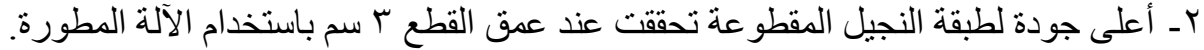

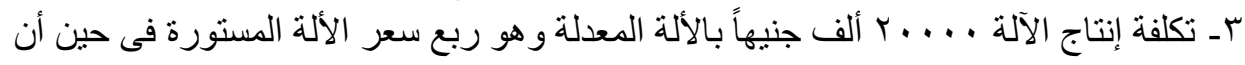
سعر الدولار 17 جنيها وتكلفة المتر مربع • ب قرش. 